\title{
Clonidine versus Tramadol as Adjuvant to Epidural Anaesthesia With 0.5\% Bupivacaine for Lower Limb Orthopaedic Procedures
}

\author{
Kumkum Gupta ${ }^{1}$, Pavitra Kalra ${ }^{2}$, Prashant K Gupta ${ }^{3}$, Salony Agarwal ${ }^{4}$, Abhishake Kumar ${ }^{5}$, Iqraa Khanum ${ }^{6}$ \\ ${ }^{1}$ Professor, Department of Anaesthesiology and Critical care, Subharti Medical College, Swami Vivekanand Subharti University, NH-58, By Pass Road, Meerut-UP, \\ India, ${ }^{2}$ Resident, Department of Anaesthesiology and Critical care, Subharti Medical College, Swami Vivekanand Subharti University, NH-58, By Pass Road, \\ Meerut-UP, India, ${ }^{3}$ Director \& Professor, Department of Radio diagnosis and Imaging, Subharti Medical College, Swami Vivekanand Subharti University, NH-58, By \\ Pass Road, Meerut-UP, India, ${ }^{4}$ Associate Professor, Department of Anaesthesiology and critical care, Subharti Medical College, Swami Vivekanand Subharti \\ University, NH-58, By Pass Road, Meerut-UP, India, ${ }^{5}$ Assistant Professor, Department of Anaesthesiology and critical care, Subharti Medical College, Swami \\ Vivekanand Subharti University, NH-58, By Pass Road, Meerut-UP, India ${ }^{6}$ Senior Resident, Department of Anaesthesiology and critical care, Subharti Medical \\ College, Swami Vivekanand Subharti University, NH-58, By Pass Road, Meerut-UP, India.
}

\section{Abstract}

Background: Epidural anesthesia is safe to provide surgical anesthesia and postoperative analgesia. Its efficacy can be improved with diversity of adjuvants. The aim of the study was to compare the clonidine versus tramadol as epidural adjuvant to $0.5 \%$ bupivacaine for lower limb orthopaedic procedures. Subjects and Methods: Sixty adult patients were enrolled and divided in two equal groups of 30 patients each to receive $14 \mathrm{~mL}$ of $0.5 \%$ bupivacaine with either $1 \mathrm{ml}(50 \mu \mathrm{g})$ clonidine (Group I) or $1 \mathrm{ml}(50 \mathrm{mg})$ tramadol (Group II), through lumbar epidural catheter at L3-L4 intervertebral space.The onset and duration of sensory and motor blockade with highest cephalic spread and duration of postoperative analgesia were assessed as primary objectives. Hemodynamic changes, respiration, sedation level or any adverse events were assessed as secondary end points. Results: Mean onset time and two dermatome sensory regression was comparable. The mean duration of sensory analgesia was $216.08 \pm 46.18$ mininpatientsof Group I and $251.33 \pm 58.5 \mathrm{~min}$ in patients of Group II with statistically highly significant difference between the groups $(\mathrm{P}=0.000)$. Mean onset time and duration of motor blockade was comparable. The hemodynamic parameters remained stable, though 4 patients of Group I developed manageable hypotension. No episode of respiratory depression, shivering, pruritus, nausea and vomiting was observed. Conclusion: Tramadol $(50 \mathrm{mg})$ as epidural adjuvantto0.5\%bupivacainewas better than clonidine for enhancing the duration of postoperative analgesia in patients undergoing lower limb orthopedic procedures.

Keywords: Bupivacaine, Clonidine, Epidural Anesthesia, Tramadol.

Corresponding Author: Prof (Dr) Kumkum Gupta Professor, Department of Anaesthesiology and Critical care, Subharti Medical College, Swami Vivekanand Subharti University, NH-58, By Pass Road, Meerut-UP, India.

Received: July 2019

Accepted: August 2019

\section{Introduction}

Epidural anaesthesia is widely used regional anaesthetic technique for lower limb orthopaedic procedures. It attenuates the stress response to surgery with enhanced duration of anaesthesia by means of an indwelling epidural catheter. Epidural anesthesia is also useful when patient is suffering from comorbid conditions or anticipated difficult airway and adverse effects of general anaesthesia can be avoided to reduce the morbidity in high risk patients. Moreover, the consciousness can be preserved during surgery ${ }^{[1]}$

Epidural blockade can be performed virtually at any level of spine but lumbar epidural blockade is simplest to perform by midline approach and its efficacy can be exalted with range of adjuvants, used either intravenously or by neuraxial route. ${ }^{[2,}{ }^{3]}$ Among adjuvants, opioids and alpha 2-adrenergic agonists could provide effective enhancement of postoperative analgesia.

Opioid analgesics activate opioid receptors located on the primary afferent neurons, resulting in the activation of pain modulating systems and suppression of action potential transmission of ascending pain pathways. Tramadol is an opioid and lacks the respiratory depressant effects despite an analgesic potency. It causes inhibition of neuronal reuptake of norepinephrine and serotonin, resulting in anti-nociceptive effect. ${ }^{[4]}$

Clonidine is centrally acting $\alpha 2$-adrenergic agonist and decreases the sympathetic nervous system outflow of norepinephrine by inhibiting the voltage gated sodium channels and prevents action potential generation in dorsal horn cells, leading to analgesia, sedation and anxiolysis without respiratory depression. ${ }^{[5,6]}$

Considering the above facts, this study was designed to compare the clinical efficacy of clonidine versus tramadol as epidural adjuvant to $0.5 \%$ bupivacaine in patients undergoing lower limb orthopaedic procedures. 


\section{Subjects and Methods}

After approval from the Institutional Ethical Committee and written informed consent, 60 patients of American Society of Anaesthesiologists (ASA) physical status I and II, aged between 28 to 58 years of either gender weighing less than $65 \mathrm{~kg}$ and scheduled for elective lower limb orthopaedic procedures under epidural anesthesia, were enrolled for this prospective randomized double blind study.

All patients underwent pre anesthetic assessment and patients with history of severe cardiac or pulmonary disease, uncontrolled hypertension, morbid obesity, hepatic or renal dysfunction, endocrinal or metabolic disorders or any coagulation disorder, were excluded from the study. Patients with deformity of spinal column, known hypersensitivity to study drugs or using any drug that modifies pain perception, infection at site of lumbar puncture were also excluded from the study.

All patients were admitted prior to day of surgery and were given tab. alprazolam $0.5 \mathrm{mg}$ and tab. ranitidine $150 \mathrm{mg}$, the night before surgery and their nil per oral status for $6 \mathrm{~h}$ was upheld on the day of surgery.

\section{Randomization Schedule}

All 60 patient were divided into two equal group of 30 patients each, according to computer generated random number table and allocation of concealment was ensured with sealed opaque envelop. Patients of Group I received 14 $\mathrm{mL}$ of $0.5 \%$ bupivacaine $(70 \mathrm{mg})$ with $1 \mathrm{ml}$ of clonidine $(50 \mu \mathrm{g})$ and patients of Group II received $14 \mathrm{~mL}$ of $0.5 \%$ bupivacaine (70mg) with $1 \mathrm{ml}$ of tramadol (50mg).

The study drug solution was premixed with isotonic saline to a total volume of $15 \mathrm{~mL}$ for both groups, prepared by resident anaesthesiologist who was restricted to collect the intraoperative data. The study was conducted in double blind manner by using coded syringes.

\section{Epidural blockade Technique}

On arrival to operation theatre, standard monitoring for heart rate, systemic blood pressure and electro cardiogram (ECG) with peripheral oxygen saturation $(\mathrm{SpO} 2)$ was commenced. Lactate Ringer solution was started after securing an intravenous line before initiation of the epidural blockade. Patients were explained about the procedure and instructed on the methods of sensory and motor blockade assessments along with VAS score agreement.

Under strict aseptic precaution, the epidural Tuohy needle was inserted between the L2-3or L3-4 intervertebral spaces through midline approach in the sitting position. An epidural catheter was advancement and fixed at the patient's back followed by alignment of patient in supine position on table. After test dose of $3 \mathrm{~mL}$ of $2 \%$ Lidocaine with epinephrine 1:200,000 and absence of any adverse effects of hypotension, bradycardia or instant motor blockade, the anaesthetic study drug solution was administered according to randomization schedule in double blind manner by using coded syringe.

Patient of Group I received $14 \mathrm{~mL}$ of $0.5 \%$ bupivacaine (70mg) with $1 \mathrm{ml}$ of clonidine $(50 \mu \mathrm{g})$ and patients of Group II received $14 \mathrm{~mL}$ of $0.5 \%$ bupivacaine $(70 \mathrm{mg})$ with $1 \mathrm{ml}$ of tramadol $(50 \mathrm{mg})$. The total premixed volume of drug solution $(15 \mathrm{~mL})$ was given through the lumbar epidural catheter. Intraoperatively, all patients were supplemented with oxygen through nasal cannula.

\section{Assessment of epidural blockade characteristics}

The sensory blockade was assessed by pin prick method bilaterally along the mid clavicular line by using short bevelled hypodermic needle and the motor blockade of the lower extremities was evaluated bilaterally by using Modified Bromage Scale (0-3):0=full movement and able to raise straight leg against resistance; 1=unable to raise extended leg at the hip but able to flex the knee; $2=$ unable to flex the knee but able to move the ankle joint; $3=$ unable to move hip, knee or ankle (no motor activity).

These blocks were assessed at every 2 minute intervals till surgical anaesthesia was achieved. After achieving the highest dermatome level, the sensory blockade was assessed every 20 minutes.

Postoperative monitoring for pain was done using Visual analogue scale (VAS) Score, in which patient specified their level of pain by indicating a position along a continuous line between two end points of $0-10$, where 0 means no pain and 10 means worst possible pain. Visual Analogue Scale (VAS) score was recorded at every 30 minutes for first hour, followed by at every $15 \mathrm{~min}$ for next two hours. At VAS score of $\geq 4$, epidural top up $(8 \mathrm{~mL}$ of $0.125 \%$ bupivacaine with $50 \mu \mathrm{g}$ fentanyl) was given for pain relief.

\section{Hemodynamic parameters}

Heart rate, systemic blood pressure, peripheral oxygen saturation $\left(\mathrm{SpO}_{2}\right)$ were recorded at baseline, after epidural blockade and thereafter at every 5 min interval till 30 minutes, then at 15 min intervals up to the end of surgery and postoperatively, at every 30 minutes interval. Any increase or decrease of more than $20 \%$ from baseline in heart rate and blood pressure was considered significant. Respiratory depression was defined when respiratory rate was less than 10 breaths/min.

Intra operative incidence of bradycardia (heart rate $<60 \mathrm{~b} / \mathrm{m}$ ) was treated with $0.5 \mathrm{mg}$ of atropine and hypotension (fall in $\mathrm{SBP}>20 \%$ of baseline value or below $90 \mathrm{~mm} \mathrm{Hg}$ ) was treated by increasing the infusion rate of lactate Ringer solution and additionally with vasopressor, if required.

\section{Sedation score}

Intraoperative sedation was recorded just after giving the epidural medication and then at every 15 minutes intervals during the surgery. Level of sedation was assessed using a five point sedation scale: 1- Alert and wide awake; 2Arousable to verbal commands; 3- Arousable to gentle tactile stimulation; 4- Arousable to vigorous shaking and 5Unarousable even on vigorous shaking.

\section{Adverse effects}

Adverse effects of nausea, vomiting, dry mouth, dizziness, respiratory depression, pruritus and shivering were recorded and managed accordingly.

\section{Study population size and statistical analysis}

The sample size was calculated in consultation with statistician who computed that 25 to 27 patients should be 
included in each group for detecting clinically meaningful difference in duration of postoperative analgesia of 30 minutes between groups for detecting type 1 error of 0.05 and power of $80 \%$ with confidence limit of $95 \%$. Thus, finally60 patients were incorporated in the study for equal distribution of patients in both groups.

The obtained data was expressed as Mean and Standard Deviation and analyzed using Stat Graphic Centurion, version 16 (Stat point technologies, IMC, Warrenton, Virginia). The demographic data for categorical variables were compared using chi-square test and statistical significance in mean difference between groups was done using student' $t$ ' test and one way analysis of variance (ANOVA). A ' $p$ ' value $<0.05$ was considered statistically significant and ' $p$ ' value $<0.001$ was considered statistically highly significant.

\section{Results}

Total 100 patients, aged between 28 to 58 years of either gender belonging to ASA physical status I and II, weighing less than $65 \mathrm{~kg}$ who scheduled for lower limb orthopaedic procedures under epidural anaesthesia, were enrolled. Out of which, 25 patients were excluded as they were not fulfilling the eligibility criteria, while 10 patients were not willing to participate and 5 patients were declined due to other reasons. Finally 60 patients were included in this study, who were randomized in two study groups by double blind manner.

\section{Demographic Profile}

The demo graphic data for age, weight, height, BMI, ASA physical status and duration of lower limb orthopaedic procedures were comparable between the groups. [Table 1]

\section{Sensory and Motor Blockade Profile}

The mean time required for onset of sensory blockade in patients of Group I was $10.06 \pm 2.03$ minute and in patients of Group II was $12.6 \pm 2.01$. The onset of sensory blockade and time to achieve T6 sensory block was faster in patients with epidural clonidine than patients of Group II, but with comparable difference $(\mathrm{p}=0.157)$.

Time from epidural medication to two dermatome sensory regression was $141.83 \pm 11.02$ minutes and $142.23 \pm 17.1$ minutes in patients of Group I and Group II respectively with comparable difference between the groups. The mean duration of sensory analgesia in patients of Group I, was $216.08 \pm 46.18$ minute and in patients of Group II, was $251.33 \pm 58.5$ minute with statistically highly significant difference between the groups $(\mathrm{p}<0.001)$.

The onset time of motor blockade was also comparable in patients of Group I (13.2 $\pm 4.30 \mathrm{~min})$ and patients of Group II $(13.93 \pm 2.74 \mathrm{~min})$. The total duration of motor block was $160.83 \pm 38.26$ minutes and $169.33 \pm 35.03$ minutes in patients of Group I and Group II respectively with statistically insignificant difference. [Table 2]

Rescue analgesia was not required in any patient till 3hoursaftergiving epidural anesthesia. The patients of Group I required first rescue analgesic after $216.08 \pm 46.18 \mathrm{~min}$, while in patients of Group II, analgesia lasted longer (251.33 $\pm 58.5 \mathrm{~min}$ ) when they required first rescue analgesia. Duration of effective analgesia was maximum in patients of

tramadol group.

\section{Hemodynamic changes}

The hemodynamic changes in patients of both groups were recorded just before commencement of epidural blockade and then at every 5 min interval still 30 minutes, then at 15 min intervals up to the end of surgery and postoperatively, at every 30 min interval.

Preoperative mean heart rate of patients of Group I and II was $91.13 \pm 14.44$ beats $/ \mathrm{min}$ and $86.06 \pm 14.22$ beats $/ \mathrm{min}$, respectively. After $5 \mathrm{~min}$ of epidural blockade, the mean heart rate in patients of Group I was decreased to $79.26 \pm 10.36$ beats/min where as it increased to $89.43 \pm 15.20$ beats/min in patients of Group II. Thereafter, the heart rate showed gradual decline in patients of both groups. After 30 min of epidural anesthesia, the heart rate became stable in patients of both groups. The changes in the mean heart rate were statistically insignificant between the groups and there was no episode of tachycardia or bradycardia in any patient. [Table 3]

Preoperative mean systolic blood pressure was127.57 \pm 10.73 $\mathrm{mmHg}$ in patients of Group I and $125.13 \pm 15.63 \mathrm{mmHg}$ in patients of Group II. After $5 \mathrm{~min}$ of epidural blockade, the systolic blood pressure decreased to $123.50 \pm 9.93 \mathrm{mmHg}$ in patients of Group I and $118.00 \pm 11.84 \mathrm{~mm} \mathrm{Hg}$ in patients of Group II with statistically insignificant difference. Thereafter, it declined constantly in patients of both groups with comparable difference. After $90 \mathrm{~min}$ of epidural anesthesia, there appeared an upwards trend in patients of Group II whereas downward trend continued in patients of Group I. The difference in mean systolic blood pressure between the groups was statistically not significant $(p>$ 0.05). [Table 4]

\section{Sedation score}

The mean sedations core in patients of Group I was2.16 \pm 0.37 and $2.20 \pm 0.40$ in patients of Group II, which remained constant till two hours after giving study drug in patients of both the groups. All patients were calm and sedated.

\section{Side Effects}

Hypotension was observed in $4(13.33 \%)$ patients of clonidine group, which was treated by increasing the infusion rate of lactate Ringer solution only. No vasopressor medication was required. No patients suffered from bradycardia, shivering, respiratory depression, pruritus, dry mouth, nausea and vomiting.

\begin{tabular}{|c|c|c|c|}
\hline Demographic data & Group I & Group II & Pvalue \\
\hline Age(year) & $35.83 \pm 6.7$ & $39.66 \pm 15.09$ & 0.209 \\
\hline Weight(kg) & $55.23 \pm 10.65$ & $54.06 \pm 9.4$ & 0.655 \\
\hline Height(cm) & $164.6 \pm 5.37$ & $162.2 \pm 6.58$ & 0.128 \\
\hline $\operatorname{BMI}\left(\mathrm{kg} / \mathrm{m}^{2}\right)$ & $20.35 \pm 3.5$ & $20.47 \pm 2.88$ & 0.894 \\
\hline ASA(I/II) & $28 / 2$ & $27 / 3$ & 0.640 \\
\hline $\begin{array}{l}\text { Duration of surgery } \\
\text { (min) }\end{array}$ & $128.45 \pm 6.31$ & $131.63 \pm 5.82$ & 0.526 \\
\hline
\end{tabular}




\begin{tabular}{l}
\hline Table 2: Sensory and Motor Blockade Profile \\
\begin{tabular}{|l|l|l|l|}
\hline $\begin{array}{l}\text { Total Duration of } \\
\text { Sensory Analgesia } \\
\text { (min) }\end{array}$ & $216.08 \pm 46.18$ & $251.33 \pm 58.5$ & $0.001^{* *}$ \\
\hline $\begin{array}{l}\text { Mean onset Time of } \\
\text { Motor Block (min) }\end{array}$ & $13.2 \pm 4.30$ & $13.93 \pm 2.74$ & 0.351 \\
\hline $\begin{array}{l}\text { Total duration of } \\
\text { motor blockade (min) }\end{array}$ & $160.83 \pm 38.26$ & $169.33 \pm 35.03$ & 0.073 \\
\hline
\end{tabular} \\
$\begin{array}{l}\text { Data are expressed as Mean and Standard deviation (SD);*P value<0.05 is statistically } \\
\text { Significant; **P value<0.05isstatistically highly significant; }\end{array}$
\end{tabular}

Table 3: Changes in Heart Rate (beats /min)
\begin{tabular}{|l|l|l|l|}
\hline Time interval & Group I & Group II & P value \\
\hline Pre-op & $91.13 \pm 14.44$ & $86.06 \pm 14.22$ & 0.176 \\
\hline After EA & $89.10 \pm 16.07$ & $86.60 \pm 15.36$ & 0.062 \\
\hline $\mathbf{5}$ min & $79.26 \pm 10.36$ & $85.43 \pm 15.20$ & 0.065 \\
\hline $\mathbf{1 0}$ min & $78.86 \pm 12.77$ & $84.53 \pm 15.51$ & 0.083 \\
\hline $\mathbf{1 5}$ min & $79.00 \pm 10.54$ & $88.26 \pm 16.56$ & 0.102 \\
\hline $\mathbf{3 0}$ min & $75.86 \pm 10.11$ & $82.6 \pm 7.11 \mathrm{~s}$ & 0.054 \\
\hline $\mathbf{4 5}$ min & $75.26 \pm 9.01$ & $82.43 \pm 8.34$ & 0.073 \\
\hline $\mathbf{6 0}$ min & $74.73 \pm 11.39$ & $80.16 \pm 5.48$ & 0.291 \\
\hline $\mathbf{9 0}$ min & $72.53 \pm 8.00$ & $81.16 \pm 2.34$ & 0.081 \\
\hline Post-op & $73.60 \pm 9.88$ & $80.83 \pm 3.47$ & 0.054 \\
\hline
\end{tabular}
\begin{tabular}{l} 
Pata expressed as Mealue $>0.05$ is statistically in significant. \\
\hline
\end{tabular}

Table 4: Changes in Systolic Blood Pressure (mmHg)

\begin{tabular}{|l|l|l|l|}
\hline Time Interval & Group I & Group II & P value \\
\hline Pre-op & $127.57 \pm 10.73$ & $125.13 \pm 15.63$ & 0.485 \\
\hline After EA & $128.20 \pm 12.93$ & $124.60 \pm 17.44$ & 0.06 \\
\hline $\mathbf{5}$ min & $123.50 \pm 9.93$ & $118.00 \pm 11.84$ & 0.061 \\
\hline $\mathbf{1 0}$ min & $124.27 \pm 7.70$ & $117.73 \pm 12.97$ & 0.078 \\
\hline $\mathbf{1 5}$ min & $120.97 \pm 9.17$ & $117.47 \pm 16.05$ & 0.073 \\
\hline $\mathbf{3 0}$ min & $113.57 \pm 12.10$ & $112.80 \pm 20.99$ & 0.863 \\
\hline $\mathbf{4 5}$ min & $108.43 \pm 9.61$ & $109.07 \pm 10.93$ & 0.813 \\
\hline 60 min & $112.43 \pm 11.55$ & $110.33 \pm 9.21$ & 0.901 \\
\hline 90 min & $110.80 \pm 11.42$ & $111.33 \pm 12.79$ & 0.865 \\
\hline Post-op & $107.77 \pm 10.42$ & $113.07 \pm 13.17$ & 0.089 \\
\hline
\end{tabular}

Data are presented as Mean and Standard Deviation; EA: Epidural Anesthesia; P value $>0.05$ is statistically in significant.

\section{Discussion}

Epidural anesthetic techniques are preferred for lower limb orthopedic procedures as duration of surgical anesthesia and postoperative analgesia could be extended by indwelling epidural catheter. Different local anesthetic can be used, but $0.5 \%$ bupivacaine is preferred. In this study, $70 \mathrm{mg}$ bupivacaine was used to establish the epidural blockade as it assured effective anesthesia for lower limb orthopedic procedures.

In augmentation strategies, range of opioids and non-opioids adjuvants are used to improve the surgical anaesthesia with enhancement of postoperative analgesia of epidural blockade. Clinical studies have shown that opioid analgesics and $\alpha 2$-adrenergic agonist administered epidurally, could relieve the visceral pain. Therefore in this study, clonidine and tramadol was used as epidural adjuvants $0.5 \%$ bupivacaine to enhance efficacy of epidural blockade and postoperative analgesia.

Clonidine induced analgesia by activation of $\alpha 2$ adrenoceptor on the dorsal horn of the spinal cord. It also rapidly absorbed into systemic circulation to reach its target sites to exert its antinociceptive action for both somatic and visceral pain. The prolongation of epidural anaesthesia may result from synergism between bupivacaine and clonidine on dorsal horn neurons.

In this study, epidural clonidine in dose of $50 \mu \mathrm{g}$ was chosen to fasten the onset of sensory blockade, which was favored by the study of Prabha $\mathrm{P}$ et al, who concluded that this dose of clonidine has significantly increased the spread and duration of analgesia as compared to bupivacaine alone in their study. ${ }^{[7]}$

Tramadol is centrally acting, $\mu$-receptor opioid agonist and exerts its effect by combining with opioid receptors in the dorsal horn of spinal cord. It enhances the function of the spinal descending pathways by inhibiting the neuronal reuptake of serotonin and norepinephrine along with presynaptic stimulation of 5-hydroxytrytamine release. In this study, tramadol in dose of $50 \mathrm{mg}$ was used as epidural adjuvant to $0.5 \%$ bupivacaine to enhance the efficacy of epidural blockade. Ramchandra VS et al also used the same dose and concluded that addition of $50 \mathrm{mg}$ tramadol to epidural bupivacaine provided good postoperative analgesia with less sedation. ${ }^{[8]}$

In this study, addition of clonidine and tramadol to epidural bupivacaine produce rapid onset and prolong the duration of sensory blockade without affecting the two segment regression time. Though sensory blockade profile was significantly better in patients of tramadol group, but mean on set of complete sensory blockade was faster in patients of clonidine group. Gupta $\mathrm{S}$ et al evaluated the analgesic effect of combination of epidural clonidine with bupivacaine and concluded that the mean onset time of sensory anaesthesia was significantly faster (493.8 \pm 31.66 seconds) in patients of clonidine group as compared to patients of control group (686.4 \pm 47.42 seconds). ${ }^{[9]}$ The results of their study was in agreement with present study.

Yaun-Shiou Huang et al conducted a dose-response study of epidural clonidine for postoperative pain after total knee arthroplasty. They divided the patients in four groups of 20 patients each, to receive patient control epidural analgesia (PCEA) with clonidine $0,1.0,2.0,4 \mu \mathrm{g} / \mathrm{ml}$ respectively and morphine $0.1 \mathrm{mg} / \mathrm{ml}$ in $0.2 \%$ ropivacaine and concluded that the highest concentration of clonidine $(4 \mu \mathrm{g} / \mathrm{mL})$ produced effective sensory and motor blockade and best analgesia, but with marked sedation, when compared to lower concentrations of clonidine. ${ }^{[10]}$

Agarwal S, Gupta K et al compared the clonidine with fentanyl as adjuvant to $0.75 \%$ ropivacaine for epidural anesthesia for lower limb surgeries. They observed that time to achieve highest sensory level and motor block was faster in patients of fentanyl group, but the duration of sensory analgesia was extended with epidural clonidine, thus delaying the need for rescue analgesia and concluded that clonidine was more effective for prolonging the duration of analgesia. ${ }^{[11]}$ 
Sutariya $\mathrm{M}$ et al randomised 90patients into three groups of 30 patients each, to receive either bupivacaine with saline, or bupivacaine with tramadol, or bupivacaine with clonidine. They concluded that onset of sensory blockade was fastest in patients of clonidine group but total duration of sensory blockade was longest in patients of tramadol group, therefore tramadol was superior ${ }^{[12]}$ The results of their study was in agreement with present study.

In this study, significantly lower VAS scores were observed in patients receiving epidural tramadol, indicating good postoperative analgesic effect. The time required for first rescue analgesic was $251.33 \pm 58.5$ min with statistically highly significant difference between the groups $(\mathrm{p}<0.001)$.

Demiraran $\mathrm{Y}$ et al compared the postoperative analgesic efficacy of single dose epidural tramadol $(2 \mathrm{mg} / \mathrm{kg})$ versus morphine $(0.1 \mathrm{mg} / \mathrm{kg})$ in children undergoing urological surgery. They observed that supplementary analgesia was not needed for 16 hours in the tramadol group and for 18 hour in the morphine group. Thus concluded that pain score and average time for analgesia were comparable in children of both groups. ${ }^{[13]}$

Prakash S et al have also evaluated the analgesic efficacy of three different doses of tramadol, administered caudally with bupivacaine to provide postoperative pain relief in 80 children. They observed that duration of analgesia was longer $(12 \pm 0.9 \mathrm{~h})$ when $0.25 \%$ bupivacaine $(0.75 \mathrm{ml} / \mathrm{kg})$ with tramadol $2 \mathrm{mg} / \mathrm{kg}$ was given by caudal route with statistically significant difference among the groups. ${ }^{[4]}$

In this study, the mean onset and total duration of motor block was neither affected by clonidine nor by tramadol, when used as epidural adjuvant to $0.5 \%$ bupivacaine. Noha Sayed Hussien ${ }^{[14]}$ and Tanmoy Ghatak et al ${ }^{[15]}$ also observed no difference in the quality of motor blocks between the groups. The result of their study was consistent with the present study. In contrast to present study Yaun-Shiou Huang et al observed that higher concentration of clonidine produced prolonged motor blockade.

During the present study, the sedation score remained constant till two hours after giving study drug in patients of the both groups. All patients were calm and sedated during the lower limb orthopedic procedures. Grand he et al also used $75 \mu \mathrm{g}$ clonidine with $0.5 \%$ hyperbaric bupivacaine and observed no significant sedation or respiratory depression in clonidine combination group. ${ }^{[16]}$

Epidural clonidine has been reported to result in intra operative hypotension. In this study, hypotension was observe din 4 patients of clonidine group which was treated by increasing the rate of crystalloid solution infusion only. No vasopressor medication was required to manage the hypotension. No other patient showed fall in blood pressure. This could be explained by adequate pre loading which was done in all patients prior to establishment of epidural blockade. No incidence of respiratory depression or changes in the respiratory rate and peripheral oxygen saturation were observed in any patient. There was no episode of nausea, vomiting or pruritus in either group. Similarly bradycardia did not occur in either group reflecting the safety of lower doses of clonidine and tramadol as epidural adjuvants in the present study.

\section{Conclusion}

Both tramadol and clonidine as epidural adjuvant to $0.5 \%$ bupivacaine could prolonged the duration of analgesia after lower limb orthopedic procedures, but sensory blockade profile of tramadol was better when compared clonidine. Hence, this study validates the use of tramadol in doses of 50 $\mathrm{mg}$ as epidural adjuvant to $0.5 \%$ bupivacaine for enhancing the sensory and motor block along with post- operative analgesia. It could also provide are usable sedation without respiratory depression and maintained the intra operative hemodynamic stability.

\section{Limitation of study}

The sample size of this study was small and a larger sample size might have more impact. The end point of this study, was demand of first rescue analgesia. Requirement of total number of analgesic doses in 24 hours could have been evaluated.

\section{References}

1. Rodgers A, Walker N, Schug S. Reduction of postoperative mortality and morbidity with epidural or spinal anaesthesia: Results from overview of randomised trials. Bri Med J 2000; 321: 1493-97.

2. Visser WA, Lee RA, Gielers MJ. Factors affecting the distribution of neural blockade by local anaesthetics in epidural anaesthesia and a comparison of lumbar versus thoracic epidural anaesthesia. Anesth Analg 2008; 107: 708-21.

3. Kock M De, Crochet B, Morimont C, Scholtes JL. Intravenous or epidural clonidine for intra and postoperative analgesia. Anaesthesiology 1993; 79: 525-31.

4. Prakash S, Tyagi R, Gogia AR, Shing R. Efficacy of three doses of tramadol with bupivacaine for caudal analgesia in paediatric inguinal herniotomy. Bri J Anaesth 2006; 97: 385- 8.

5. Khan ZP, Ferguson CN, Jones RM. Alpha-2 and imidazoline receptor agonists. Their pharmacology and therapeutic role. Anesthesia 1999;54:146-65.

6. Upadhyay KK, Prabhakar T, Handa R, Beena H. Study of the efficacy and safety of clonidine as an adjunct to bupivacaine for caudal analgesia in children. Ind J Anaesth 2005; 49: 199-201.

7. Prabha P, Shreya Vathi, Syed Imran, Prarthana BP, Pradeep MS. The effect of addition of clonidine to low dose bupivacaine for unilateral inguinal herniorrhaphy: A randomized double blinded study. Sch J App Med Sci 2014;2: 1-7.

8. Ramchandra Vinayak Shindhaye, Bhawini Bhushan Shah, Smita Suresh, Shrikrishna Govind Deogankar, Abhishek $\mathrm{P}$ Bhuva. Comparison of clonidine and fentanyl as an adjuvant to intrathecal bupivacaine for spinal and postoperative analgesia in patients undergoing caesarean section. Sri Lankan J Anaesthesiol 2014; 22: 1520.

9. Gupta S, Raval D, Patel M, Patel N, Shah N. Addition of epidural Clonidine enhances postoperative analgesia: A double-blind study in total knee- replacement surgeries. Anesthesia, Essays and Researches 2010; 4: 70-4.

10. Huang Yuan-Shiou, Lin Liu-Chi, Huh Billy K. Epidural clonidine for postoperative pain after total knee arthroplasty: A dose-response study. Anesth Analg 2007; 104: 1230-5.

11. Agarwal S, Gupta K, Gupta PK, Bansal M, Sharma R, Aqsa Buchh. Clonidine versus fentanyl as adjuvant to $0.75 \%$ Ropivacaine for epidural anesthesia for lower limb surgeries: a comparative evaluation. Int J Res Med Sci 2016; 4: 3606-10.

12. Sutariya M, Amin AJ, Beth AB. A comparative study of clonidine versus tramadol as additive to bupivacaine in epidural anaesthesia. Int J Cur Res Rev 2016; 8: 11-18.

13. Demiraran Y, Kocaman B, Akman RY. A comparison of the postoperative analgesic efficacy of single dose epidural tramadol versus morphine in children. Bri J Anaesth 2005; 95: 510-3.

14. Noha Sayed H. A comparative study between magnesium sulphate and clonidine as adjuvant to epidural anesthesia in patients undergoing 
abdominal hysterectomy. Ain- Shams Journal of Anaesthesiology 2011; 4: 1-9.

15. Ghatak T, Chandra G, Malik A, Singh D, Bhatia VK. Evaluation of the effect of magnesium sulphate vs. clonidine as adjunct to epidural bupivacaine. Ind J Anaesth 2010; 54: 308-13.

16. Grandhe RP, Wig J, Yaddanapudi LN. Evaluation of bupivacaineclonidine combination for unilateral spinal anesthesia in lower limb orthopaedic surgery. J Anaesthsiol Clin Pharmacol 2008; 24: 155-8.

Copyright: ( $)$ the author(s), publisher. Academia Anesthesiologica International is an Official Publication of "Society for Health Care \& Research Development". It is an open-access article distributed under the terms of the Creative Commons Attribution Non-Commercial License, which permits unrestricted non-commercial use, distribution, and reproduction in any medium, provided the original work is properly cited.

How to cite this article: Gupta K, Karla P, Gupta PK, Agarwal S, Kumar A, Khanum I. Clonidine Versus Tramadol as Adjuvant to Epidural Anaesthesia With 0.5\% Bupivacaine for Lower Limb Orthopaedic Procedures. Acad. Anesthesiol. Int. 2019;4(2):164-69.

DOI: dx.doi.org/10.21276/aan.2019.4.2.37

Source of Support: Nil, Conflict of Interest: None declared. 